\title{
A RETROSPECTIVE STUDY: OSTEOPOROSIS AND HORMONE REPLACEMENT THERAPY
}

\author{
H. June Kuczynski and Mary L. Rogers
}

Osteoporosis, an important health hazard associated with the menopause, is characterized by a reduction in the quantity of bone without changes in its chemical composition. It is defined as a decrease in height by $25 \%$ of at least one vertebra, determined by X-ray examination (Riggs, Seeman, Hodgson, Taves and O'Fallon, 1982). ' The skeleton is unable to maintain its mechanical integrity, and fractures result. Osteoporosis

-ffects all bones of the body, but fractures -ccur primarily in the cancellous bone of the femur, vertebrae, distal forearm, humerus, and ribs.

The true epidemiology of osteoporosis has only recently been appreciated. Hip fractures are much more frequent in elderly women than in men the same age and women of any age who undergo oophorectomy attain bone density comparable to that of postmenopausal women (Meema, S. and Meema, H., 1976). ${ }^{2}$ The process of bone loss accelerates alarmingly following cessation of ovarian function, amounting $1 \%$ to $3 \%$ of total bone mass per year (Horsman, Simpson, and Kirby, 1977; Johnston, Norton, and Khan, 1978; Lindsay, et al., 1976). ${ }^{3}$ 's The Caucasian woman reaching eighty will thus lose $30 \%$ to $50 \%$ of her original bone mass.

Undoubtedly, the dynamic equilibrium of bone deposition and resorption is extremely complex and relies on delicate terrelationship between dietary calcium mtake and absorption, serum concentrations of calcium and phosphorus, and the secretion of parathyroid hormone, calcitonin, and vitamin D (Hammond, and Maxson, 1982). ${ }^{6}$ The precise mechanism of the action of oestrogen of bone metabolism is unknown. Oestrogen therapy appears to increase intestinal and renal tubular absorption of calcium. Oestrogen also appears to inhibit bone resorption, perhaps by decreasing the response of bone to circulating parathyroid hormone or by directly changing parathyroid levels (Hammond and Maxson, 1982). ${ }^{7}$ Although the role of oestrogen in the pathogenesis of postmenopausal osteoporosis is unclear, there remains a close relationship between osteoporosis and the age at the cessation of ovarian function (Horman, Simpson, and Kirby, 1977). ${ }^{8}$

The prevention of postmenopausal osteoporosis with HRT is an important area of research. Considering the fact that women can expect to live one-third of their lives postmenopausally, prevention is the

\section{Abstract}

The purpose of this study was to determine if women who undergo hormone replacement therapy postmenopausally, will demonstrate less osteoporosis than women who do not undergo HRT. The osteoporosis subjects were 195 women who volunteered to participate in an NIHsponsored double-blind clinical trial entitled Safety and Efficacy of Fluoride Therapy in Osteoporosis. A convenience sample of 78 controls was obtained by inviting women seeking regular medical attention to join an epidemiological investigation of osteoporosis.

The data were analyzed using Chisquare and Student's t-ratio. The study concludes that future retrospective and prospective analyses appreciate the complexity of the problem in terms of individual risk for osteoporosis.

ultimate goal of therapy. Unfortunately, once bone mass has declined to the point that ordinary stress causes fractures, little can be done except to repair the fractures.

Continued investigation into the epidemiology of osteoporosis with respect to oestrogen use or non-use will advance knowledge of prevention of the disease. While the outcome of prospective studies designed to evaluate the benefits and risks is awaited, retrospective analysis is useful. Comparison of women with osteoporosis to women free from the disease in terms of HRT is one method for elucidating the relationship between HRT and bone status.

Purpose of the Study

The purpose of the study was to determine if women who undergo HRT postmenopausally, will demonstrate less osteoporosis than women who do not undergo HRT postmenopausally.

\section{Research Questions}

1. How does the osteoporosis group compare with the control group in terms of hormone therapy use measured by a yes or no response?

2. How does the osteoporosis group compare with the control group in terms of hormone therapy use in years?

3. How does the osteoporosis group compare with the control group in terms of arbitrary divisions of time of hormone therapy use $(\leq 5, \geq 6$ years, or $\leq 10, \geq 11$ years)?

\section{Conceptual Framework}

Orem's model of self care stresses health maintenance, disease prevention, and patient participation in health-care services. One of the premises of self care is that it is based on deliberate and thoughtful judgement which leads to appropriate action. Orem views human beings as self-care agents. Self care is the practice of activities that individuals personally initiate and perform on their own behalf in maintaining life, health, and well-being (Orem, 1985). ${ }^{9}$ In Orem's model, nursing systems are wholly or partly compensatory, or educativesupportive. The educative-supportive nursing system is the primary means employed to correct deficits which emerge when the self care-agency is less than the therapeutic self-care demand. Knowledge, motivation, values, membership in social and cultural groups, and skill influence the practice of self care. Assumed in the theory is that adults have the right and responsibility to care for themselves and that self care contributes to the self esteem of the person and is directly related to self concept.

Menopause is looked upon as a nursing situation where the health focus is oriented to the life cycle, care being designed to promote and maintain health and to protect against specific diseases and injuries such as osteoporosis. The advisability of HRT depends on current and future research that nurses undertake on behalf of their women clients. As answers to research questions accumulate, nurses are in a superior position to design nursing systems that will enhance theorybased self-care practices.

\section{Limitations}

Hormone use and durations were recorded according to anamnestic data. The dose and name of hormones used remained uncertain in most cases. It is speculated that some seventy-year olds may not remember the duration of hormone use accurately. Thus, there is a limitation imposed by the data collection procedure. 
In addition to a deficit of data on hormone dosage, the number of years since the last menstrual period and the initiation of HRT was not assessed. This has been shown significant in at least one investigation cited. There was also the possibility that controls may have had vertebral fracture and this was not directly assessed by spinal X-ray. Finally, subjects were not matched on age, diet and lifestyle, or height and weight for practical reasons inherent to the design of the study.

\section{Literature Review}

The problem of postmenopausal osteoporosis was first documented by Albright (1940). ${ }^{10} \mathrm{He}$ observed that the majority of patients with significant bone demineralization affecting the entire skeleton, but particularly the vertebral column, were females whose ovaries had been removed or were several years postmenopause. He demonstrated that in such cases, oestrogen produced a positive calcium and inorganic phosphate balance. Newer isotope techniques that measure bone density have reinforced the clinical observations of Albright and others. Women who are still menstruating in their 50 's retained their youthful bone mass, but after the menopause there was a linear loss of bone tissue. Oophorectomy causes a similar loss of bone in premenopausal women. Dual beam X-ray spectrophotometry shows that trabecular bone is preferentially lost after oophorectomy in the three sites where postmenopausal women sustain fractures: vertebrae, wrists, and hips (Dalen, Lamke and Wallgren, 1974). ${ }^{11}$

Lindsay, Hart, Forrest, and Baird (1980) reported that long term continuation of oestrogen replacement therapy (mean of 9 years, with a range of 6 to 12 years) has shown no significant loss of bone mass in a treated group with a progressive loss of bone in a placebo group. Study patients were 100 post-oophorectomy women. Additionally, when oestrogen therapy has been discontinued, even after long periods of administration, rapid and progressive loss of bone results. ${ }^{12}$

Prevention of postmenopausal osteoporosis may not be unique to oestrogens since therapy with an injectable progesterone is also effective in preventing bone loss. At least three studies have shown that progesterone plus oestrogen may actually increase bone mass by promoting new bone formation (Christiansen, C., Christiansen, M. McNair, Hagen Stockland, and Transbol, 1980; Christiansen, C., Christiansen, M., \& Transbol, 1981; Nachtigall, L., Nachtigall, R.H., Nachtigall, R.D., and Beckman, 1979). ${ }^{\text {i3-15 }}$

Other studies emphasize that oestrogen therapy should be initiated early and suggests that oestrogens are beneficial to osteoporotic women, regardless of age. Benefits of treatment 5 to 15 years after menopause were shown by Recker, Saville, and Heaney (1977), and as late as the age of 70 years by Jensen and Christiansen (1982). . $^{16.17}$
A recent study by Ettinger, Benant, and Cann (1987), ${ }^{18}$ examined the rate of bone loss in untreated women undergoing spontaneous menopause and tested for possible protective effects of oestrogen and calcium. Research on calcium supplementation has recently become a primary area for investigation. They found significant losses in spinal trabecular mineral content (measured by quantitative computed tomography), in untreated women and in women given calcium supplements alone (1 $500 \mathrm{mg}$ daily). No significant changes were observed in women receiving oestrogen with calcium. This study appears to be in agreement with that of Riis, Thomsen, and Christiansen (1987) whose data suggest that calcium supplementation is not as effective as oestrogen therapy for the prevention of postmenopausal bone loss. ${ }^{19}$ In comparison to oestrogen treatment, which prevents bone loss throughout the skeleton, calcium treatment as compared with a placebo, had a minor effect in slowing cortical bone loss, but not trabecular bone loss.

In addition to vertebral collapse, loss of height, and kyphosis, osteoporosis also results in the notably high rates of Colles's fractures and hip fractures. When evaluating postmenopausal oestrogen therapy in terms of fracture prevention, several studies point to its effectiveness. Weiss (1985) reported that the risk of fracture was $50 \%$ to $60 \%$ lower in women who had used oestrogens for 6 years or longer, compared to women who had not used oestrogens. In addition, the risk of fractures was least in the patients who were currently taking oestrogen at the time of the study whether the dose was ,625 $\mathrm{mg}$ or $1,25 \mathrm{mg}$ daily. Bone mineral content and metacarpal bone mass were significantly greater in the long-term treated group. ${ }^{20}$

The protective action of oestrogens is of major medical, social, and economic concern. A long term recommendation on oestrogen-progesterone prophylaxis still awaits knowledge of all the possible advantages and disadvantages. Recent findings have encouraged a more liberal attitude. Most important, cyclic oestrogenprogesterone appears to reduce markedly or even eliminate the risk of endometrial cancer. A significant correlation between oestrogen and breast cancer is currently unsubstantiated. At least two reports have actually indicated a decrease in the risk of breast cancer in women in the menopausal period (Gambrell, Maier, and Sander, Sander, 1983; Gambrell, Massey Castaneda, and Boddie, 1980). ${ }^{21,22}$ Several recent investigations have found an inverse relationship between oestrogen use and risk of coronary disease (Bush, et al., 1983; Stampfer, et al., 1986). ${ }^{23,24}$

\section{Method}

This study was undertaken to find evidence that oestrogen protects bones in postmenopausal women. This retrospective study was part of a large double-blind controlled clinical trial sponsored by the National Institute of Health, entitled
Safety and Efficacy of Fluoride Therapy in Osteoporosis. The data were collected at a large Detroit Metropolitan Hospital, from September 1981 to January 1984. The study received Human Subjects Clearance in 1982 .

\section{Sample}

The osteoporosis group was selected from the general population by soliciting white women between the ages of 45 and 75 with osteoporosis to join a double-blind clinical trial for treatment of osteoporosis. Although most candidates resided in the Detroit Metropolitan area, wide publication of the study brought participants from New York, California, Ohio, Indiana, and Arizona. Clients eligible for the study had spontaneous menopause at least 12 months before entry into the study and had at least one vertebral fracture by $\mathrm{X}$-ray examination to affirm a diagnosis of osteoporosis. Women with clinical evidence of bone disease and those with any medical condition that could predispose to bone loss were excluded. Clients taking certain medications, presently or in the past known to affect bone activity were also excluded. Of the 409 women interviewed, 195 fulfilled the aforementioned inclusion criteria. Subjects were required to sign a written consent form prior to entry into the study.

A convenience sample of control subjects was obtained from a population of women seeking regular medical attention at other medical Metro branches. All white women between the ages of 45 and 75, who had experienced menopause and were free from osteoporosis, were invited to join an epidemiological investigation of postmenopausal osteoporosis. Participants agreed to be interviewed by a research nurse after their regular appointment. A prior chart review ruled out clients with diagnosed osteoporosis, the same exclusion criteria were applied to both groups. Of the 87 women interviewed, 78 were suitat for inclusion. A verbal explanation of the purpose of the interview was given to each subject.

\section{Instrument}

The research instrument was designed specifically for the NIH sponsored study of osteoporosis, of which the present study was a part. A completed draft of the questionnaire was ready for use in September of 1981 when interviewing of study patients began. The questionnaire contains four parts: (1) patient characteristics, (2) diet and lifestyle, (3) physical examination, and (4) medications. Menstrual history was included in part 1 and provided the data for the present study. The three questions pertaining to HRT were (a) Have you used hormones since the menopause? (b) What type of preparation was used? (c) What was the duration of use? A weakness in the design was the absence of a question on hormone dose. Although dosage was sometimes recorded, it is not certain whether the 
question was always put forth by the interns and residents who also used the form. The supposition that most women would not know or remember the dosage lacks direct evidence. In any event, lack of sufficient data on hormone dose excluded it from statistical analysis. In all other respects, the interview schedule proved adequate as a screening tool and for collection of epidemiologic information.

\section{Procedure}

The verbal explanation of the research given to study patients emphasized the screening procedure necessary to establish the eligibility of the client for the clinical trial. It was explained that the questionnaire to be filled out by the research nurse was the first step in the screening procedure and that the information would also be used for researching factors related to osteoporosis. Control subjects were told that a large group of women with osteoporosis had been interviewed and that presently more information was needed on normal men. All participants were interviewed in a private room an average of 20 minutes.

\section{Data Analysis Plan}

Following completion of data collection, analysis (including mean and standard deviation) was done for descriptive purposes. Age was included in the analysis with application of Student's t-ratio. The data related to hormone use or non-use were analyzed using the chi-square test. Student's t-ratio was used to analyze data related to duration of hormone therapy in years. Length in years of hormone therapy was divided arbitrarily into two time periods: $<5,>6$ years, and $<10,>11$ years. The chi-square test was used for this analysis.

\section{RESULTS \\ mographic Data}

The osteoporosis sample consisted of 195 subjects with a mean age of 65,6 years, SD 6,6 years. The control sample consisted of 78 subjects with a mean age of 63,3 years, SD 7,6 years. This difference did prove statistically significant, $t(201)=2,63$, $<, 05$.

\section{Testing of Research Questions:}

\section{Hormone therapy use.}

The data indicate that hormone therapy use was not significantly greater in control group, as might be expected, than in the osteoporosis group with $\mathrm{X}^{2}(1, \mathrm{~N}=268)$ $=, 39, \mathrm{p}<, 05$.

Duration of hormone therapy in years.

Neither the osteoporosis group or the control group reported a significantly greater duration of HRT, $t(258)=1,1$, $\mathrm{p}<, 05$ (see Table 1).

Time interval comparison of HRT duration.

No significant differences were found between the osteoporosis group and the
TARLE: 1

Mean Duration of HRT in Osteoporosis and Control Groups

$\begin{array}{lll} & \text { Osieo } & \text { Control } \\ N= & 184 & 76 \\ \text { Mean }= & 2,12 \text { years } & 2,21 \text { years } \\ \text { SD }= & 5,72 \text { years } & 4,57 \text { years }\end{array}$

\begin{tabular}{|c|c|c|c|}
\hline \multicolumn{4}{|c|}{ TABIE 2} \\
\hline \multicolumn{4}{|c|}{$\begin{array}{l}\text { Mean I ength of Hormone Therapy (in Years) According to } \\
\text { Two Time Divisions }\end{array}$} \\
\hline Osteo & Conirel & Mean Yrs. & SD \\
\hline $\begin{array}{lr}\leq 5 \text { years } & 156 \\
\geq 6 \text { years } & 28\end{array}$ & $\begin{array}{r}68 \\
8\end{array}$ & $\begin{array}{r}0,79 \text { years } \\
13,50 \text { years }\end{array}$ & $\begin{array}{l}1,32 \text { years } \\
6.69 \text { years }\end{array}$ \\
\hline Total 184 & 76 & & \\
\hline Missing Dala 7 & 1 & & \\
\hline $\begin{array}{l}\leq 10 \text { years } 168 \\
\geq 11 \text { years } 416\end{array}$ & $\begin{array}{r}76 \\
4\end{array}$ & $\begin{array}{r}1,43 \text { years } \\
18,82 \text { years }\end{array}$ & $\begin{array}{l}2,51 \text { years } \\
5,98 \text { years }\end{array}$ \\
\hline Total 184 & 78 & & \\
\hline Missing Data 7 & 1 & & \\
\hline
\end{tabular}

control group in terms of length of hormone therapy, using two arbitrary time frames for analysis. When comparing a five years or less usage period with a six years or more usage period $X^{2}(1, N=260)$ $=, 96, \mathrm{p}<, 05$. When comparing a 10 years or less usage period with an 11 years or more usage period $\mathrm{X}^{2}(1, \mathrm{~N}=260)=, 92$, $\mathrm{p}<, 05$ (see Table 2).

\section{DISCUSSION AND \\ RECOMMENDATIONS}

Using personal interviews to determine oestrogen exposure, neither controls or clients with osteoporosis show a high prevalence of past exposure. Additionally, controls did not demonstrate appreciably longer mean duration of HRT. Following the pattern of previous research on longbone and hip fracture, a significant relationship is expected in terms of each research question posed. However, the use of the vertebral fracture as a means of osteoporosis, as in the present study, had not been tested in published investigations to date.

It has been found that the number of years since the last menstrual period has a significant effect on response to HRT. Therefore, a lack of data on this variable is a limitation in the present study. It is possible, for example, that many of the osteoporotics used HRT long after menopause, while controls may have used HRT in the immediate postmenopausal period. Lack of this data can be attributed to a fault in the design of the questionnaire. Lack of data on dosage is also unavailable for analysis due to omission on the questionnaire. A colour display of oestrogen-containing preparations could be used to facilitate the participants' recall.

Many other variables have been suggested as possible risk factors for osteoporosis, such as early age at menopause, low weight, height ratio, physical activity, heavy alcohol use, cigarette smoking, low dietary calcium intake, and high dietary phosphate consumption. Oral contraceptives may play a role in osteoporosis prevention. Breastfeeding patterns and parity also deserve consideration. In the present study, the mean number of children is 2,08 for osteoporotics and 2,95 for controls. Perhaps childbearing has a protective effect on the bones. Certainly all of these variables merit analysis. The assumption was made that the two groups did not differ in any important way with respect to these variables.

One striking feature of the control sample noted by mere observation, is shortness of stature combined with relative obesity. The average height and weight of controls is $5 \mathrm{ft}, 146 \mathrm{lb}$. while the osteoporotics measure $5 \mathrm{ft}, 1$ in., $140 \mathrm{lb}$. with a mean self-reported height loss of 2,37 in. (controls reported a mean loss of 1,02 in., attributable to ageing alone). Using Quetelet's index (the body weight of an adult ought to be as many $\mathrm{kg}$ as his body length in centimetres exceeds 100 ) as a measure of obesity, there is a tendency for women with a high weight for height ratio to be at low risk for fracture. This association is attributed to the protective effect of high endogenous oestrogen production in obese women.

The osteoporosis group is found to be slightly older than the control group, the difference reaching statistical significance. Considering that participants were not matched for age and the acceptable age range was quite large, the difference was fortunately small.

For practical and economic reasons, controls did not have spinal $\mathrm{X}$-ray to eliminate a diagnosis of osteoporosis. This might have shown that several had vertebral fracture. All charts were reviewed to find persons whose chest or spine $X$ rays reported a fracture. The $X$-ray was then examined and measured to make a diagnosis. Unfortunately, vertebral fractures are not routinely reported by radiology unless that is the diagnosis to be specifically ruled out. Self-report of height loss in the control group was small, further limiting a missed diagnosis of osteoporosis However, data would be more accurate if actual height was measured at the time of interview as in the osteoporosis group. All charts were reviewed for height at most recent physical examination and discrepancies corrected.

Surveys of postmenopausal women, such as the present study, point to the inconsistencies in the prescription of HRT after the menopause. Outcome of treatment that is based on specific reasons for prescribing HRT deserves analysis. It would be helpful, for instance, to look at a group who were placed on HRT based on some amount of risk for osteoporosis and a group at similar risk that did not receive HRT.

The relation of differences in prescribing practices to differences in beliefs about the risks and benefits of HRT is an area ripe for investigation. Elstein et al. (1986) compared physician's decisions regarding HRT for menopausal women and decisions derived form a decision analytic model. It was found that treatment was 
withheld despite the clinician's own beliefs about the risks and benefits of HRT, possibly in order to avoid rare but very undesirable outcomes at the expense of exposing women to far more common, but less undesirable consequences. ${ }^{25}$ For example, the increased probability of early detection of cancer by regular follow-up was systematically incorporated into the decision analysis by unheeded in unassisted clinical judgement, which adheres to the tenet of minimizing the most important risk, notwithstanding its probability. It cannot be forgotten that the literature of the 1970's emphasized the relationship between oestrogen and endometrial cancer while the 1980's has focussed on HRT and its role in osteoporosis prevention. There is, perhaps, a lag between changes in opinion and practice patterns. Nurses, particularly those in primary care, need to be sensitive to the indications for HRT based on the most current opinions and research.

Nurse researchers in the area of women's health are natural candidates for undertaking projects that will ultimately mean improved health for women well after the menopause. In future retrospective analyses of a similar nature, it would be prudent to take the number of years since LMP into account as well as drug dosage. Actual height measurements and spinal $X$-rays on all patients are recommended. Accounts needs to be taken of the many possible confounding variables previously enumerated. Ideally subjects would be matched for various factors such as weight, height, alcohol intake, tobacco intake, and physical activity. Parity, breastfeeding patterns, and oral contraceptive use are recommended areas for study. Finally, more research is needed in area of prescribing practices.

The association between osteoporosis and HRT is difficult to study from an epidemiologic standpoint. Studies have been handicapped by a lack of a uniform standard of diagnosis. The skeletal benefit of HRT measured by reduction in the incidence of vertebral fractures needs further research, prospectively and retrospectively. Belief in causality would be greatly enhanced if different study designs attained congruous results. Through continuous research efforts, women clients can know the risks and benefits of HRT in order to participate in decisions affecting their health and as part of the self-care philosophy.

\section{REFERENCES}

1. Riggs B.L., Seeman E., Hodgson S.F., Taves D.R., O'Fallon W.M. Effect of the fluoride/calcium regimen on vertebral fracture occurrencein postmenopausal osteoporosis. New England Journal of Medicine, 1982; 306, 446-450.

2. Meema S., Meema He.E. Menopausal bone loss and estrogen replacement. Israeli Journal of Medical Science, 1976; 26, 33-338.

3. Horsman A., Simpson M., Kirby P.A. Nonlinear bone loss in oophorectomized women. British Journal of Radiology, 1977; 50, 504-508.

4. Johnston C.C., Norton J.A., Khairi R.A. (1978) Age-related bone loss. In U.S. Barzel (ed.), Osteoporosis. (Vol. 2, pp. 91-124). New York: Grune \& Stratton.

5. Lindsay R., Hart D.M., Aitken J.M., McDonald E.B., Anderson J.B., Clark A.C. Long-term prevention of postmenopausal osteoporosis by oestrogen: evidence for an increased bone mass after delayed onset of oestrogen treatment. Lancet, 1976, 1, 1038-1040.

6. Hammond C., Maxson W. Current status of estrogen therapy for the menopause. Ferility and Sterility, 1982; 37, 5-25.

7. Hammond C., Maxson W. Current status of estrogen therapy for the menopause. Fertility and Sterility, 1982; 37, 5-25.

8. Horsman A., Simpson M., Kirby P.A. Nonlinear bone loss in oophorectomized women. British Journal of Radiology, 1977; 50, 504-508.

9. Orem D. (1985) Nursing: Concepts of Practice. New York: McGraw-Hill.

10. Albright F., Smith P H., Richardson H.M. Postmenopausal osteoporosis: Its clinical features. Journal of the American Medical Association, 1974; 116, 2465-2470.

11. Dalen N., Lamke B., Wallgreen A. Bonemineral losses in oophorectomized women. Journal of Bone and Joint Surgery, 1974; 56, 1235-1238.

12. Lindsay R., Hart D.M., Aitken J.M., McDonald E.B., Anderson J.B., Clark A.C. Long-term prevention of postmenopausal osteoporosis by oestrogen: evidence for an increased bone mass after delayed onset of oestrogen treatment. Lancet, 1976, 1, 1038-1040.

13. Christiansen C., Christiansen M.S., McNair P., Hagen C., Stocklund K., Transbol I. Prevention of early postmenopausal bone loss: controlled 2-year study in 315 normal females. European Journal of Clinical Investigation, 1980; 10, 273-276.

14. Christiansen C., Christiansen M.S., Transbol I. Bone mass in postmenopausal women after withdrawal of oestrogen/progestogen replacement therapy. Lancet, 1981; 1, 459-461.

15. Nachtigall L., Nachtigall R.H., Nachtigall R.D., Beckman E. Estrogen replacement therapy I: A 10-year prospective study in the relationship to osteoporosis. Obstetrics and Gynecology. 1979; 53, 277-281.

16. Recker R.R., Saville P.D., Heaney R.P. Effects of estrogen and calcium carbonate on bone loss in postmenopausal women. Annals of Internal Medicine, 1977; 87, 649-665.

17. Jensen G.F., Christiansen C., Transbol I. Fracture frequency and bone preservation in postmenopausal women treated with estrogen. Obstetrics and Gynecology, 1982; 60, 493-496.

18. Ettinger B., Genant H.K., Cann C.E. Postmenopausal bone loss is prevented by treatment with low-dosage estrogen with calcium. Annals of Internal Medicine, 1987 106, 40-45.

19. Riis B.J., Tomsen K., Strom V., Christiansen $C$. The effect of percutaneous estradiol and natural progesterone on postmenopausal bone loss. American Journal of Obstetrics and Gynecology 1987; 156, 61-65.

20. Weiss K (ed.). Women's Health Care: $A$ Guide to Allernatives. Reston, Virginia: Prentice-Hall, 1985.

21. Gambrell R.D., Maier R.C., Sander B. Decreased incidence of breast cancer in postmenopausal estrogen-progesterone user Obstetrics \& Gynecology, 1983; 62, 435-443.

22. Gambrell R.D., Massey F.M. Castaneda T.A., Boddie A.W. Estrogen Therapy and breast cancer in postmenopausal women. Journal of the American Geriatric Society, 1980; 28, 251-257.

23. Bush R., Cowan L.D., Barret-Connor E., Criqui M.H., Karon J.M., Wallace R.B., Tyroler H., Rifkind B.M. Estrogen use and all-cause mortality: Preliminary results from the Lipid Research Clinics Program followup study. Journal of American Medical Association, 1983; 249, 903-906.

24. Stampfer M.J., Willet W.C., Colditz G.A., Rosner B., Speizer F.E., Hennekens C.H. A prospective study of postmenopausal estrogen therapy and coronary heart disease. New England Journal of Medicine, 1986; 313, 1044-1048.

25. Elstein A.S., Holzman G.B., Ravitch M.M., Metheny W.A., Holmes M.M., Hoppe R.B., Rothert M.L., Rovner D.R. Comparison of physicians' decisions regarding estrogen replacement therapy for menopausal women and decisions derived from a decision analytic model. American Journal of Medicine, 1986; 80, 246-258.

"I June Kuczinski, Ph.D., M.S.N., R.N., S.C.M.

Professor and Chair

Dept. of Maternal-Child Health. Walne

State Universitl. Detroit, Michigan

Mary L. Rogers, M.S.N., R.N.

Consultant, Brighton, Michigan

The authors wish to acknowledge the help of Dr. Michael Kleerekoper. Medical Direcior, Henry Ford Hospital, Detroit, Michigan. 